\title{
PHARMACOECONOMIC MODELS IN RHEUMATOLOGY
}

\author{
K. Tachkov', V. Boydzhieva ${ }^{2,3}$, Z. Mitkova', N. Stoilov',3, G. Petrova² \\ ${ }^{1}$ Faculty of Pharmacy, Medical University - Sofia \\ ${ }^{2}$ Medical Faculty, Medical University - Sofia \\ ${ }^{3}$ Clinic of Rheumatology - University Hospital "Sv. Ivan Rilski "
}

\begin{abstract}
Pharmacoeconomic models of chronic diseases explore the development of the disease, patients' pathways through it and calculate the cost-effectiveness of the therapy with different medicines. The goal of the current study is to identify the pharmacoeconomic models used in rheumatology, their historical development and utilization. Systematic search in PubMed was performed with key words "pharmacoeconomic, models, rheumatology, and cost-effectiveness". On total 58 manuscripts were identified, describing mainly the rheumatoid arthritis development. The first one in line is the ACCES model of rheumatoid arthritis which have been validated in Sweden, Norway, etc. This is one of the first Markov models in rheumatology. Biological medicines are in the primary area of interest for modelling their therapeutic results. During the latest year scientists are working for the development of the web based platform to forecast the biological therapy (model PREDIRA). In alliance with other therapeutic areas with the development of artificial intelligence the pharmacoeconomic models is expected to increase, especially those built with data from real world clinical practice.
\end{abstract}

Key words: pharmacoeconomics, modelling, rheumatology, cost-effectiveness

\section{INTRODUCTION}

Pharmacoeconomic analyzes aim to support the choice between available therapeutic alternatives in the treatment of specific diseases [1]. In the process of conducting them, rules of good research practice are followed in order to ensure the most reliable information and support decision-makers in an objective and impartial manner [2]. The choice of alternatives to therapeutic behavior must ensure the best investment for society without compromising the quality of health care [3]. For this purpose, a connection is needed between clinicians, pharmacoeconomists and drug regulators in the development of the design of the analyzes and the selection of appropriate methods and indicators for the evaluation of the therapeutic results [4].

Pharmacoeconomic models are one of the most commonly used methodological tools for presenting the course of the disease, the therapeutic process and the behavior of patients during treatment [5]. They use a wide range of data - epidemiological, data from randomized clinical trials and real clinical practice, expense related data, the probabilities of occurrence of a therapeutic result etc. [6]. These data serve to build an analytical, computational tool that allows to describe the therapeutic process, to predict the future behavior of patients, to calculate the cost of treatment and the expected therapeutic results [7]. The ultimate goal is to calculate the cost-effectiveness ratio for different behavioral alternatives and to support decision making.

Chronic, progressive diseases, among which are a large part of rheumatic diseases, have a probabilistic course in certain groups of patients and allow the application of probabilistic models. [8]. Studies of the types of pharmacoeconomic models in the field of rheumatology are limited, which provokes our interest in this topic.

The aim of the present work is to identify the pharmacoeconomic models used in rheumatology and the directions of their construction and development.

\section{MATERIALS AND METHODS}

A systematic study of PubMed publications with the keywords "pharmacoeconomic, models, cost-effectiveness, rheumatology" was conducted. The PubMed database was chosen because it references scientific journals in the field of medicine. There are no restrictions on the year of publication and the language of publication. The identification of publications also covers those proposed by the system, as related to the topic of the search.

The search results are presented in the PRISMA diagram in Figure 1. 


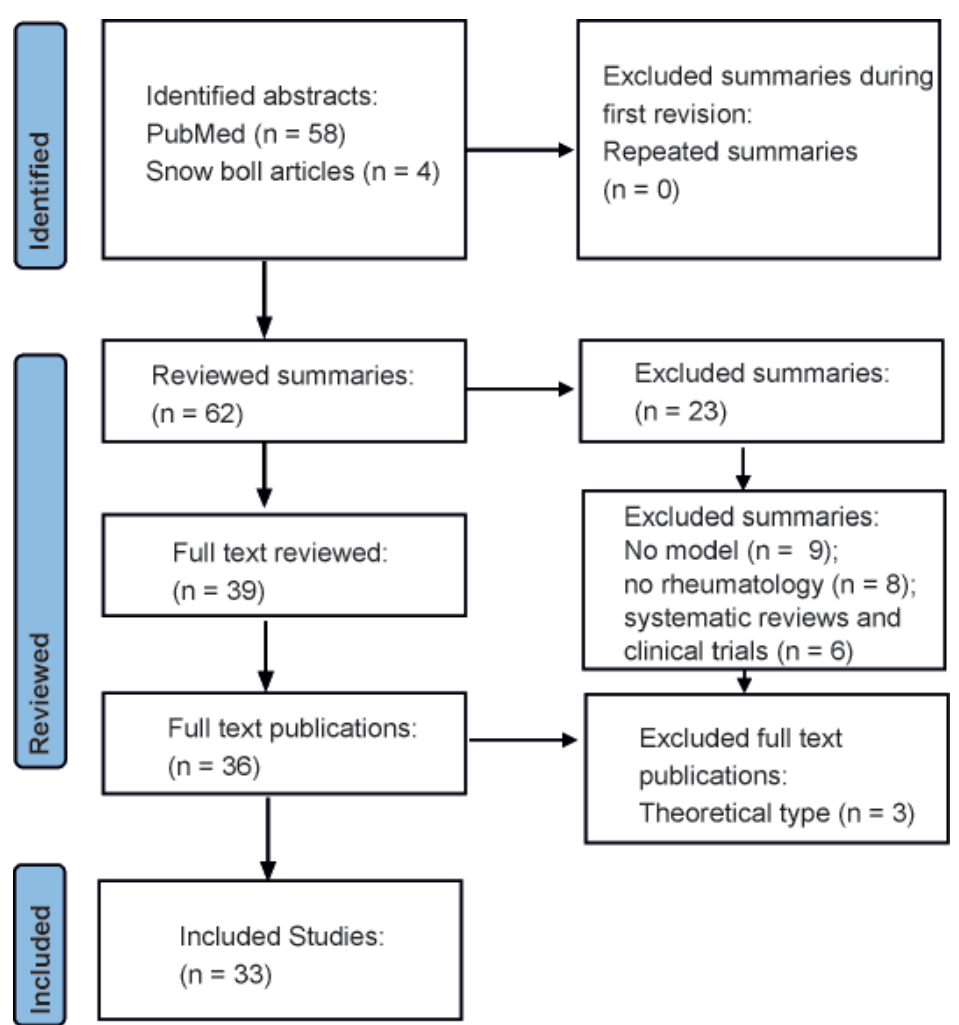

Fig. 1. PRISMA flow diagram for selection of studies [9]

\section{RESULTS}

Table 1 summarizes the included publications on the main characteristics of the pharmacoeconomic studies described by Drummond et al [10]. The diagnoses for which models have been developed are rheumatoid arthritis (27 publications), gout (2 publications) and one publication each for psoriasis, psoriatic arthritis, ankylosing spondylitis and osteoarthritis. New biological molecules have been evaluated in 26 of the publications, JAK inhibitor tofacitinib in one, and coxibs in three publications. The majority of publications are conducted from the perspective of the paying institution and therefore direct medical costs are included, and only one includes indirect costs.
Therapeutic outcome measures were either quality of life measures in 15 publications (QALY, quality-adjusted life year) or disease activity measures, among which low disease activity measured on the American College of Rheumatology and Health Assessment Questionnaire scales (HAQ).

Regarding the used pharmacoeconomic method, out of the 33 publications included one describes only the costs for treatment of rheumatoid arthritis, 23 aim to apply the cost-effectiveness method, 2 apply the cost-benefit method - 2; in one publication both cost-effectiveness and cost-utility are applied; in two cost-effectiveness and analysis of the budget impact are explained, in 3 publications an economic assessment was conducted and in one the benefits and risks were assessed.

In all pharmacoeconomic studies, except one, biological therapy was assessed as cost-effective, even for some health care systems as cost-saving.

The models used in the publications are Markov models $(n=15)$; patient-level simulation models ( $n$ $=5)$; modeling of discrete events $(n=3)$; population model $(n=2)$; decision tree $(n=2)$; linear regression model in cost analysis $(n=1)$; budget impact model $(\mathrm{n}=2)$.

Since the object of this publication are the models used, in the subsequent analysis we will pay more attention to their structure and to the most frequently used ones.

One of the first publications presents the socalled ACCES model in the evaluation of celecoxib, which has been used in several countries. The model uses the decision tree technique to present results and consequences in the treatment of patients with celecoxib compared to other non-steroidal anti-inflammatory drugs (NSAIDs) (Figure 2).

Table. 1. Scenarios in a microsimulation model at the patient level (Navarro F., et al., 2020)

\begin{tabular}{|c|c|c|c|c|c|}
\hline \multirow{2}{*}{$\begin{array}{l}\text { Scenario } 1 \\
\text { DMARDs population }\end{array}$} & Tofacitinib $2 x d+$ MTX & Rituximab + MTX & Tocilizumab sc + MTX & Etanercept + MTX & Certolizumab + MTX \\
\hline & Adalimumab + MTX & Rituximab + MTX & Tocilizumab sc + MTX & Etanercept + MTX & Certolizumab + MTX \\
\hline \multirow{2}{*}{$\begin{array}{l}\text { Scenario } 2 \\
\text { DMARDs population }\end{array}$} & Tofacitinib 2xd + MTX & Adalimumab + MTX & Rituximab + MTX & Tocilizumab sc + MTX & Etanercept + MTX \\
\hline & Baricitinib + MTX & Adalimumab + MTX & Rituximab + MTX & Tocilizumab sc + MTX & Etanercept + MTX \\
\hline \multirow{2}{*}{$\begin{array}{l}\text { Scenario } 3 \\
\text { TNFi population }\end{array}$} & Tofacitinib $2 x d+$ MTX & Abatacept sc + MTX & Rituximab + MTX & \multicolumn{2}{|c|}{ Certolizumab + MTX } \\
\hline & Tocilizumab sc + MTX & Abatacept sc + MTX & Rituximab + MTX & \multicolumn{2}{|c|}{ Certolizumab + MTX } \\
\hline \multirow{2}{*}{$\begin{array}{l}\text { Scenario } 4 \\
\text { TNFi population }\end{array}$} & Tofacitinib 2xd + MTX & Tocilizumab sc + MTX & Abatacept sc + MTX & \multicolumn{2}{|c|}{ Rituximab + MTX } \\
\hline & Tocilizumab sc + MTX & Abatacept sc + MTX & Rituximab + MTX & \multicolumn{2}{|c|}{ Certolizumab + MTX } \\
\hline
\end{tabular}




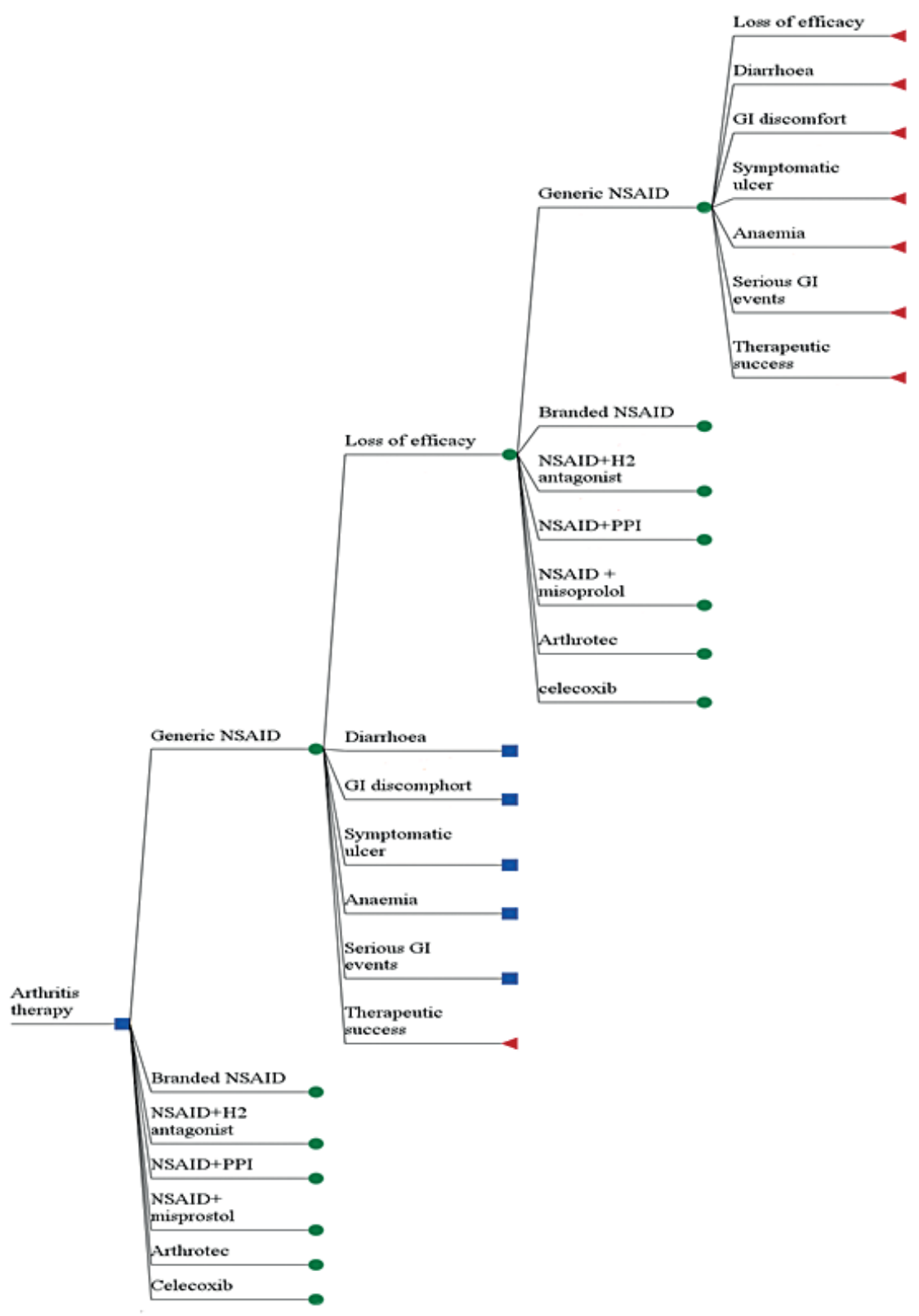

Fig. 2. Structure of the ACCES model (Svarvar P et al, 2000)

This model compares seven possible therapeutic behaviors in the treatment of arthritis, six of which are NSAIDs as monotherapy or in combination with other products. The branches of the decision tree represent therapeutic success, loss of efficacy, and the occurrence of adverse drug reactions (ADRs). Data from clinical practice and brief product characteristics were used for the incidence of ADRs. The treatment steps are repeated without specifying the treatment recurrence period, but it is stated that the time can vary between 0 and 365 days, so we as- sume that the treatment period is one year. The results are measured by years of life saved or the frequency of ADR, and the costs are those of the payer. A calculator in excel program for application of the model has been developed. The decision to choose a therapeutic alternative is made on the basis of the saved costs of prevented ADRs or the cost of a year of life saved. The advantages of this modeling technique are its flexibility in terms of therapy duration, compared alternatives, uncertainty calculations. It is possible for the input parameters to vary according 
to the method of treatment and national characteristics.

The second model is a simulation-type decision tree for comparing two biological products after an inadequate response to previous treatment with a biological product in moderate to severe RA (Figure 3 ). The simulation model of the decision tree type allows to calculate variable distributions.

The publication presents 12 separate models developed to simulate 6 consecutive changes in therapy, consisting of 3 biological medicines. The results of the treatment were measured by 2 measures of therapeutic success - remission and low disease activity. The costs are direct medical costs. Data on the effectiveness of biologic therapy are taken from clinical trials published at the time of the model development in 2012.

A patient-level microsimulation model for health system purposes in Spain was developed to assess the sequence of tofacitinib treatment followed by biologic versus biologic therapy alone. Four scenarios for changing the treatment of patients have been developed (Figure 4).

Model parameters include demographic and clinical data [HAQ]. and response to long-term treatment. Efficacy was measured by changes in

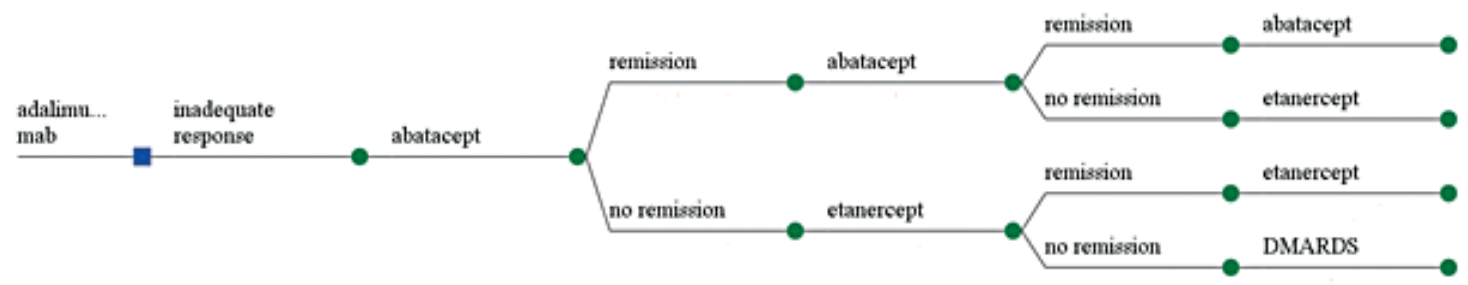

Fig. 3. Example of a simulation Model tree of solutions for second-line biological therapy (Puolakka K. et al., 2012)

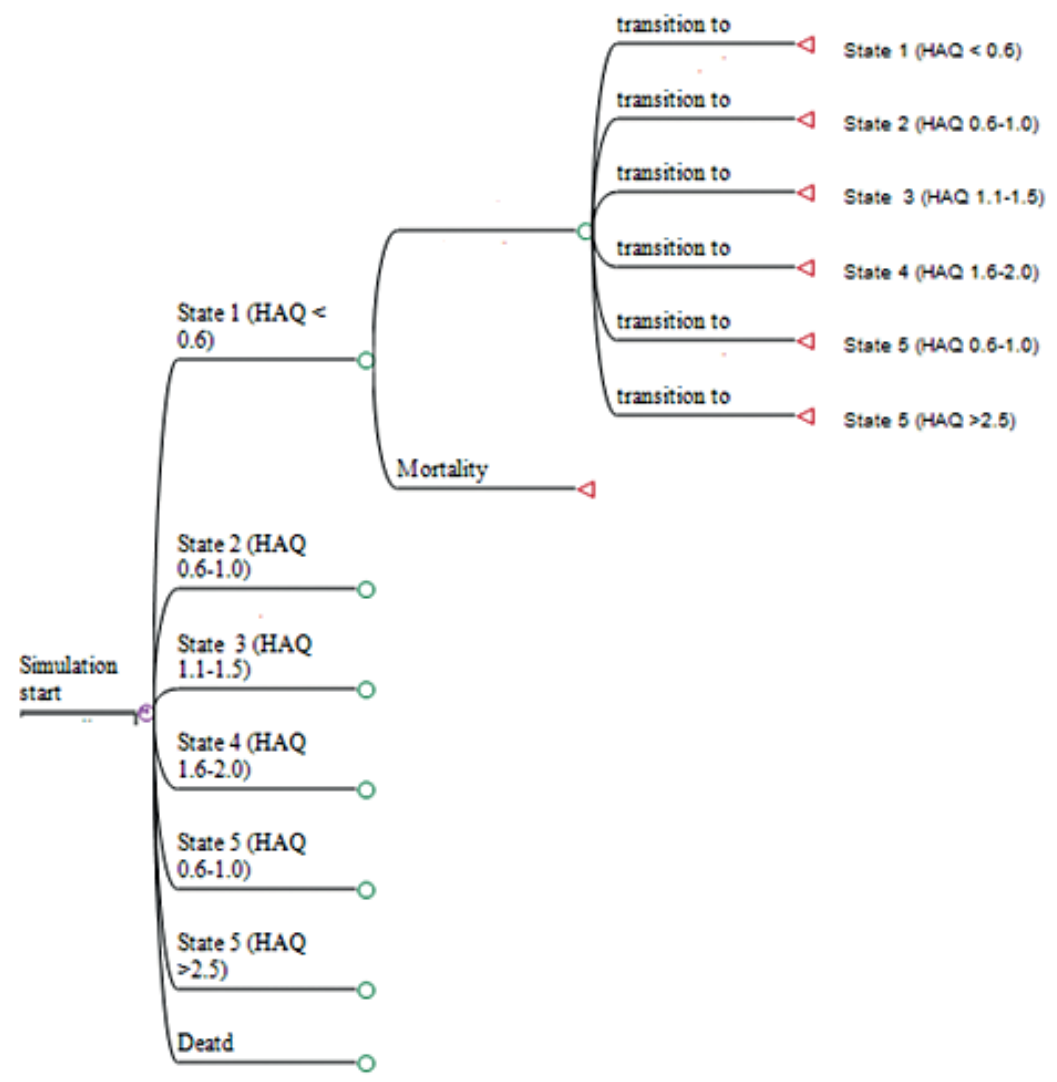

Fig. 4. Scheme of a Markov model for the treatment of RA (Kobelt G., 2003) [12] 
$H A Q$ values. Serious side effects are also included in the model. The costs are direct medical expenses and include expenses for medicines, parenteral administration, disease progression, treatment of serious ADRs.

One of Markov's first models was developed by Kobelt et al. to illustrate the progression of RA, which was subsequently used to assess the cost-effectiveness of infliximab in the treatment of RA - Figure 4. The model compares two treatment alternatives and non-treatment, with transitions from condition to condition being determined by changes in values of $H A Q$. Condition 1 has the lowest level of disability $(\mathrm{HAQ}<0.6)$ and condition 6 has the highest degree of disability (HAQ02.6). After each one-year cycle, the model redistributes patients to each condition based on changes in HAQ values. Absorbing state is death. Data on the efficacy of infliximab as an alternative treatment in the second model were extrapolated from the ATTRACT clinical trial.

The model of Russell et al. examines transition states between low disease activity and remission when comparing abatacept and disease modifying antirheumatoid drugs (DMARDs). A similar transition is used by the model of lannazzo et al. The model of Welsing et al. uses the DAS (disease activity score) as a measure of disease activity to describe patients' transition between health conditions when extrapolating short-term data from clinical trials.

Another Markov model initially described the sequence of the therapeutic process with the hitherto known medicinal products (Figure 5), and then, based on the therapeutic behavior and data from clinical trials, created a model with a transition from ACR exacerbation conditions (Figure 6).

\section{Discussion}

This publication complements previous developments in the field of therapeutic process modeling and the application of drugs in rheumatology. [14]. Undoubtedly, pharmacoeconomic models are increasingly used for mathematical description of treatment and prediction of its future development, as well as the cost-effectiveness of new molecules [15-49].

This work confirms that models for the treatment of rheumatoid arthritis predominate, and to a lesser extent for other rheumatological diagnoses.

With the introduction of new organic products, we can expect that the number of models will increase due to the requirements of regulatory institutions to prove the cost-effectiveness of new health and pharmaceutical technologies. However, these types of models are sometimes too schematic, as they target only a specific drug and use information about the therapeutic effect of clinical trials, which does not give a complete picture of all available alternatives on the market. More important are the models that describe the course of the disease in its treatment and compare more than two alternative behaviors [48, 49].

This study shows that the models in rheumatology are very limited in number compared to other therapeutic areas, such as endocrinology and diabetes. This is probably due to the individual course of the disease and the difficulty of including all possible treatment options. With the development of artificial intelligence and its wider application in the processing of data from real clinical practice, these problems will be overcome.

The current study has some limitations. In the first place, it includes publications only from PubMed. We have tried to overcome this limitation by including other studies recommended by the system, but there are probably models that are missing. Another limitation is that it does not include national surveys.

\section{Conclusion}

Pharmacoeconomic models in rheumatology are primarily for rheumatoid arthritis as the most common diagnosis. There is still no complete description of the development of the main rheumatological diagnoses. As in other therapeutic areas, with the development of artificial intelligence the importance of pharmacoeconomic models will increase, where these models are built with data from studies in real clinical practice. 


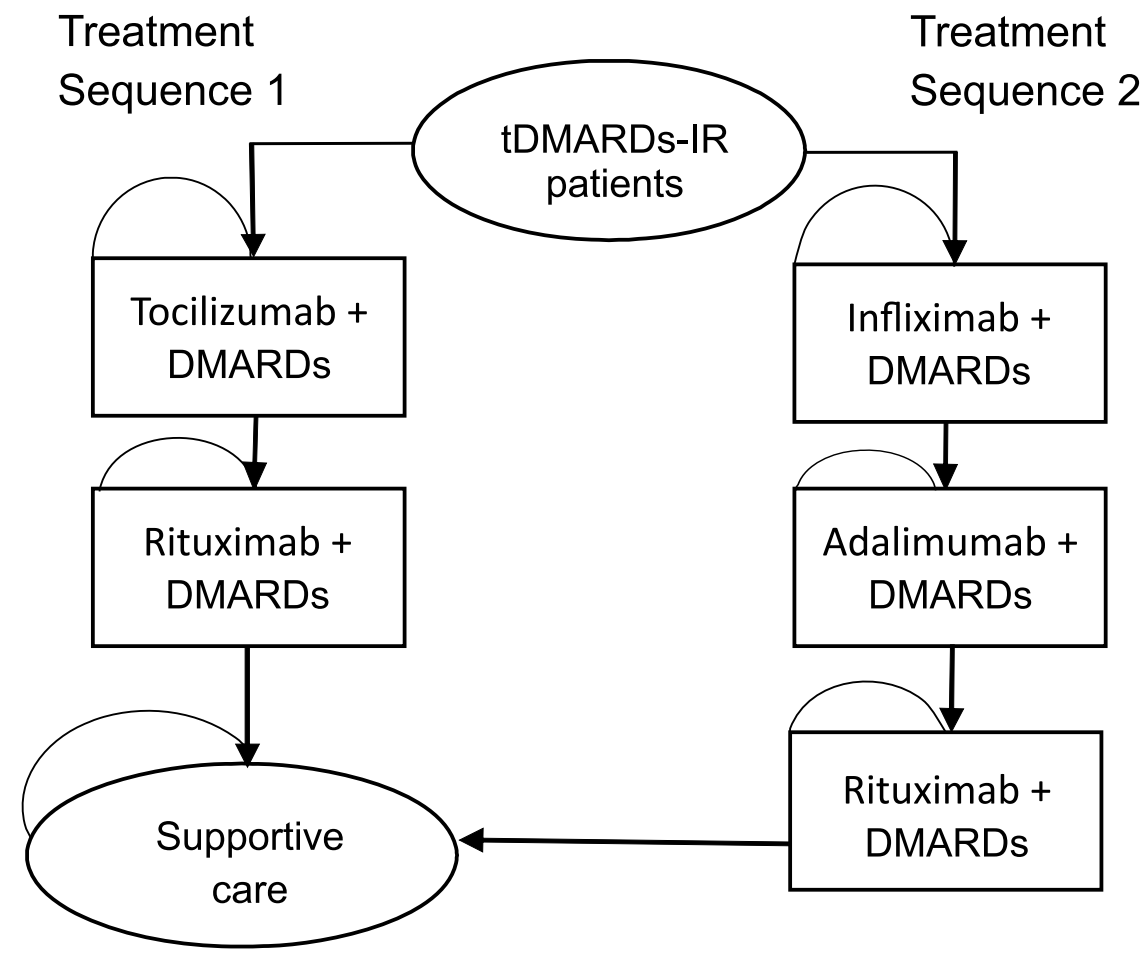

Fig. 5. Scheme of therapeutic process according to Hashemi-Meshkini A., 2016 [13]

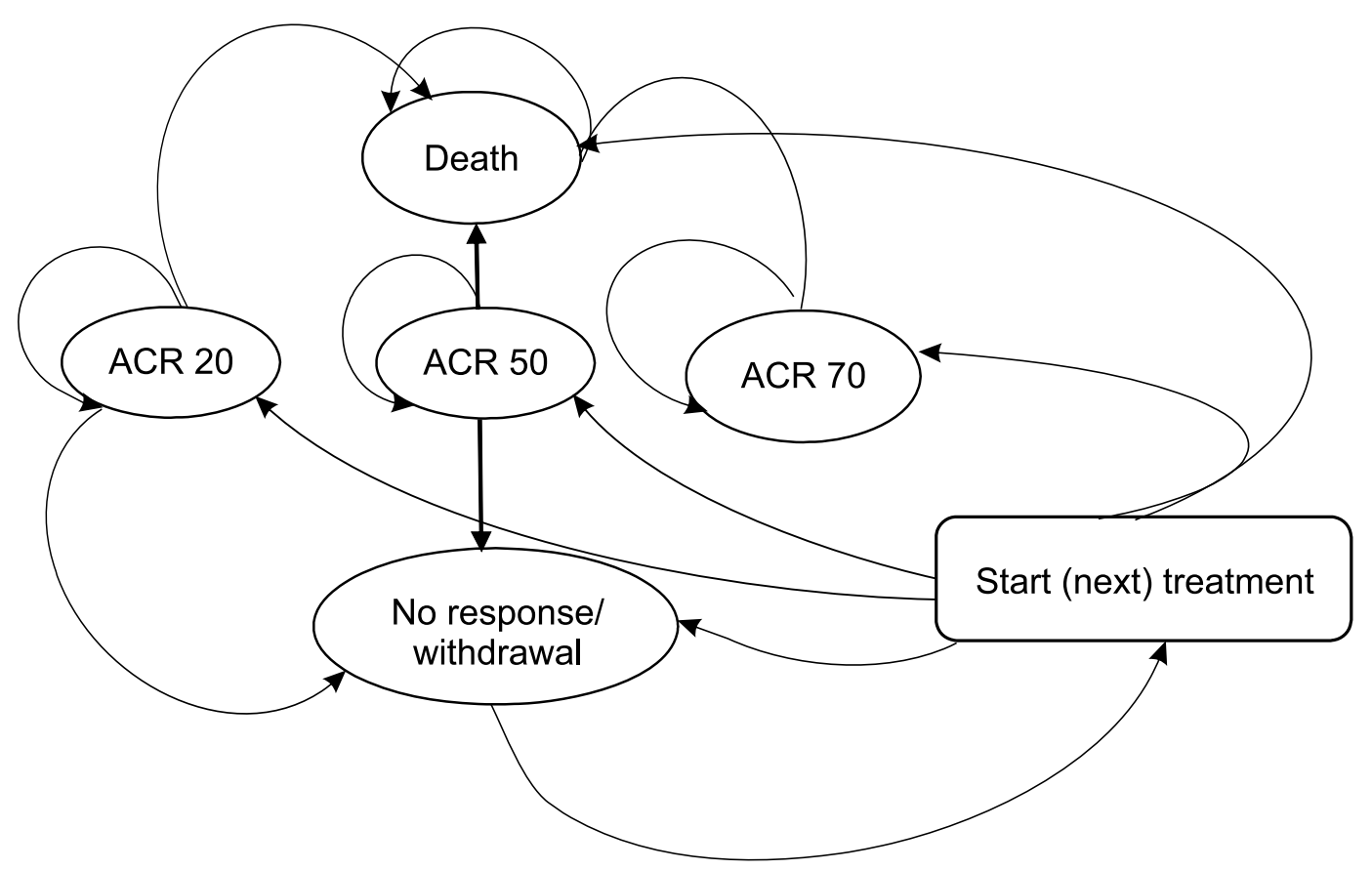

Fig. 6. Structure of transitions in RA according to Hashemi-Meshkini A., 2016 


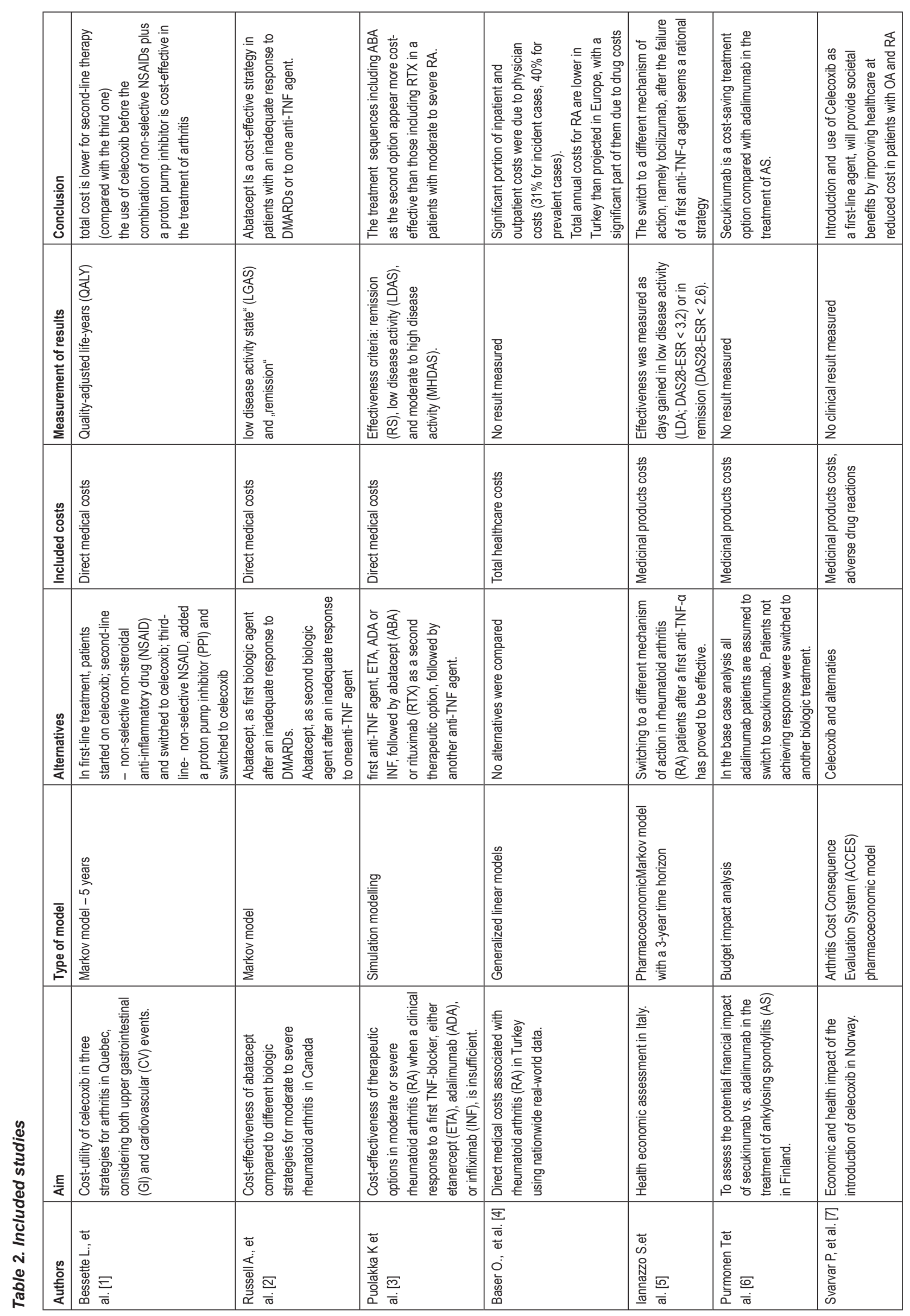




\begin{tabular}{|c|c|c|c|c|c|c|}
\hline 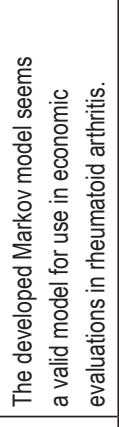 & 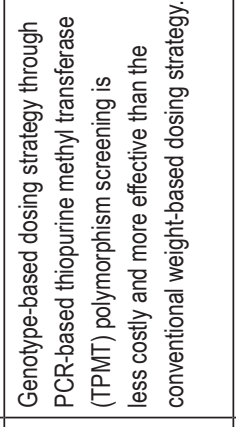 & 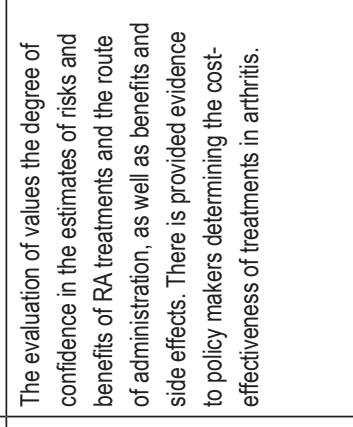 & 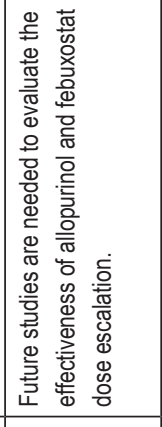 & 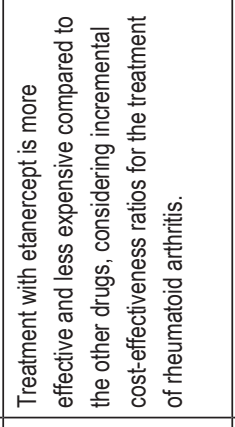 & 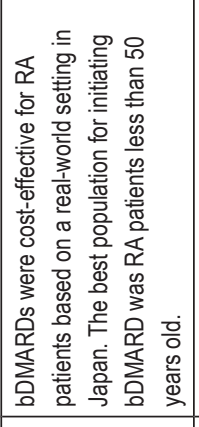 & 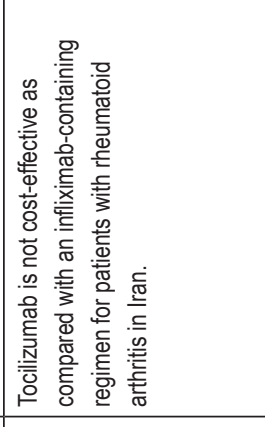 \\
\hline خे & 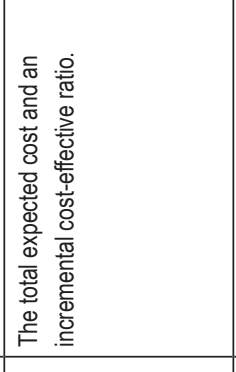 & 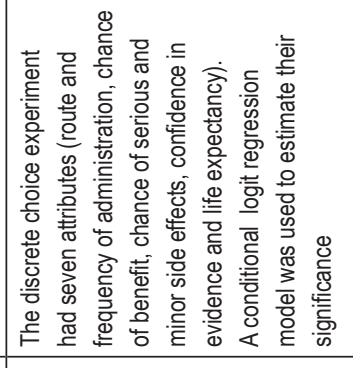 & 文 & 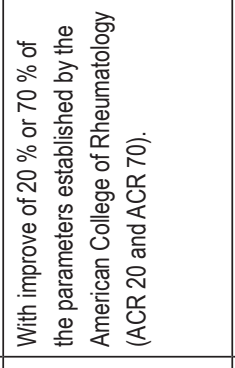 & 文 & $\frac{2}{8}$ \\
\hline 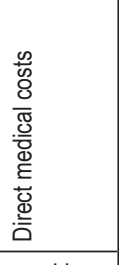 & 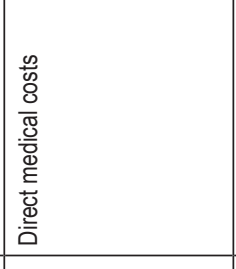 & 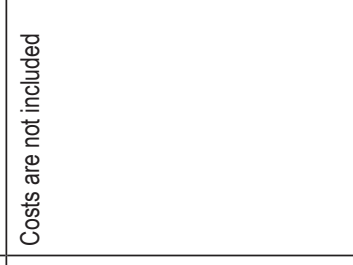 & 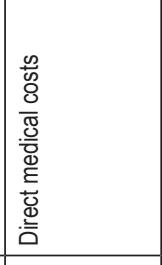 & 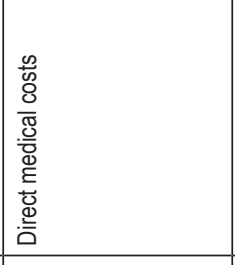 & 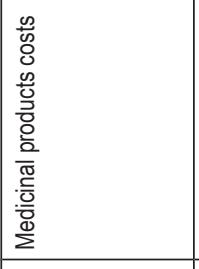 & 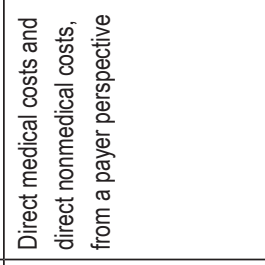 \\
\hline 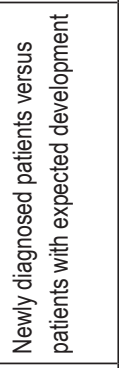 & 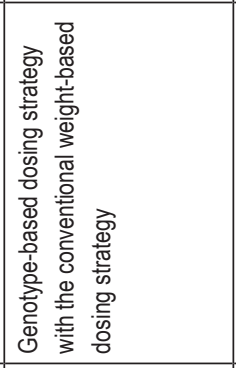 & 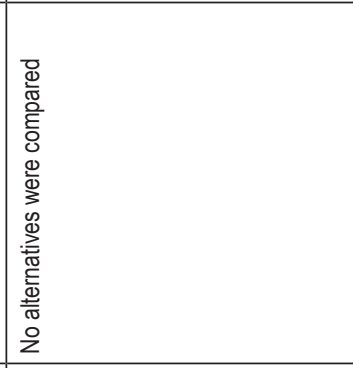 & 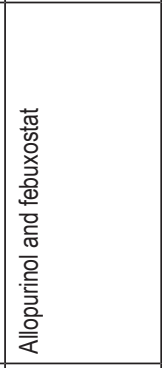 & 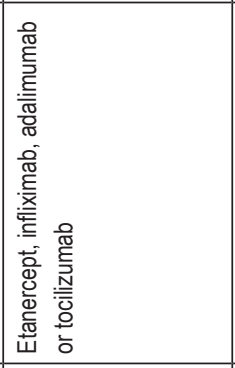 & 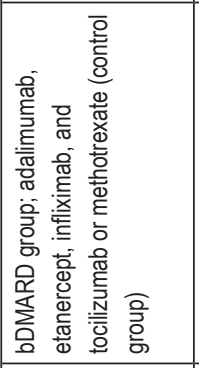 & 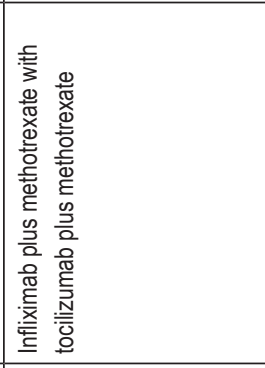 \\
\hline 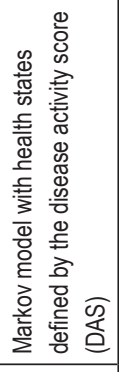 & 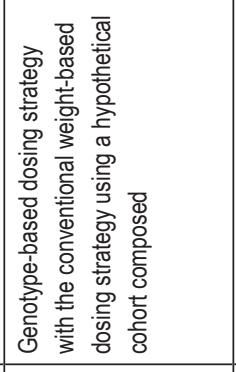 & 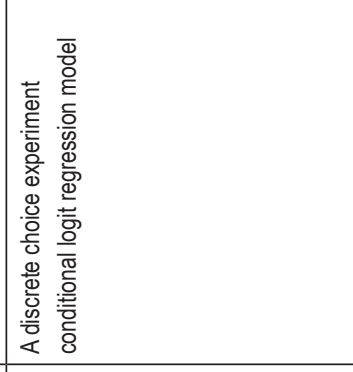 & 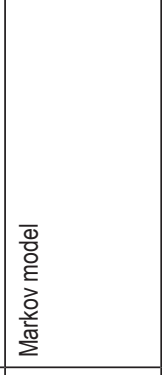 & 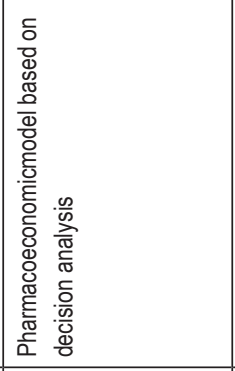 & 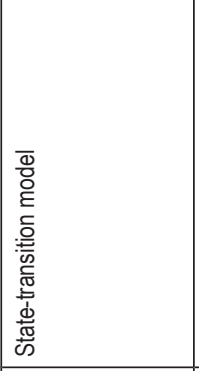 & 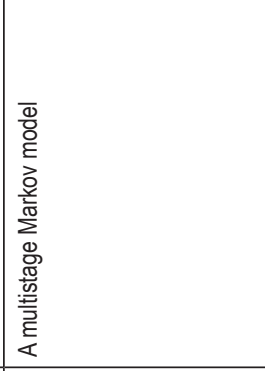 \\
\hline 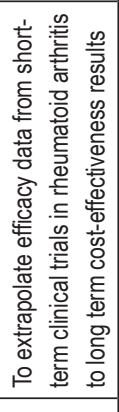 & 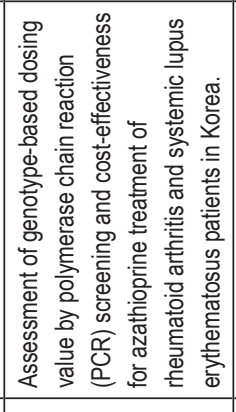 & 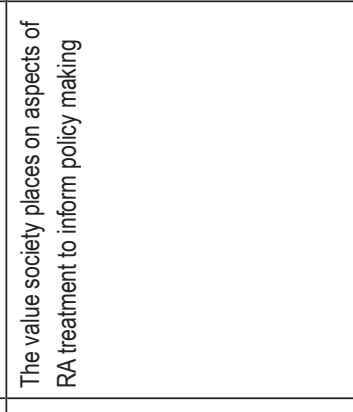 & 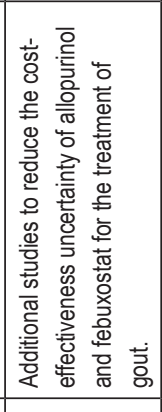 & 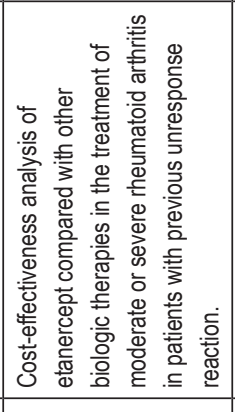 & 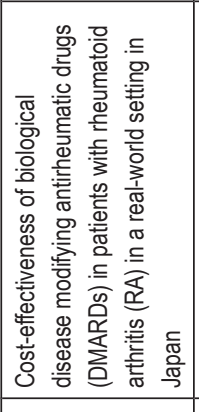 & 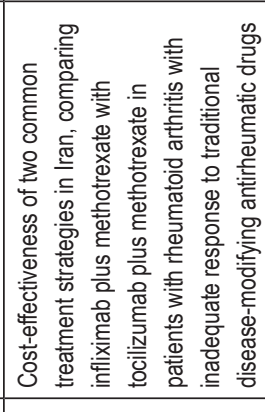 \\
\hline 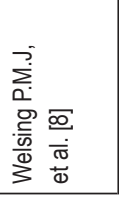 & 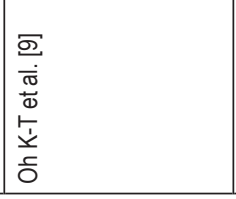 & 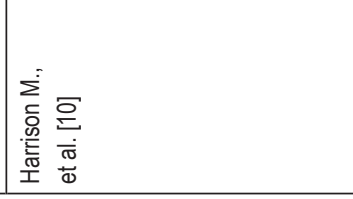 & 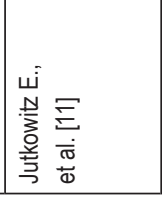 & 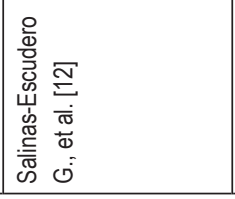 & 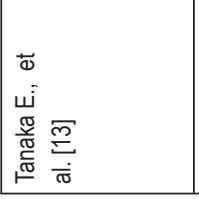 & 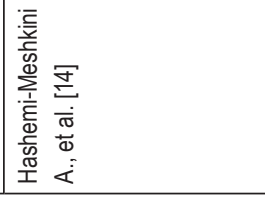 \\
\hline
\end{tabular}




\begin{tabular}{|c|c|c|c|c|}
\hline 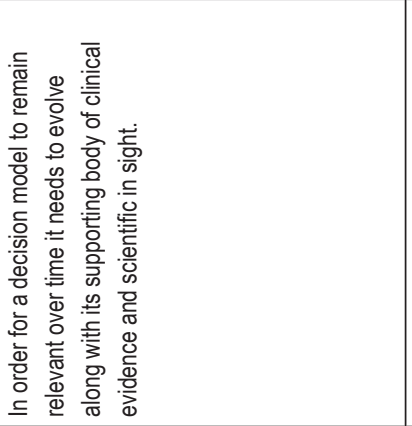 & 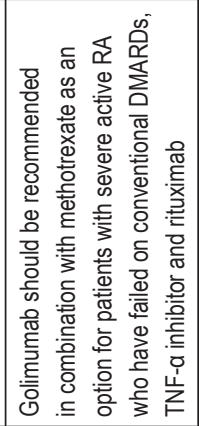 & 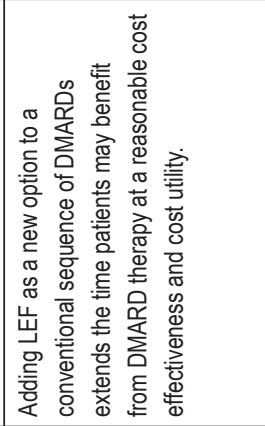 & 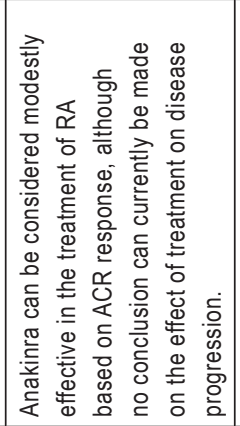 & 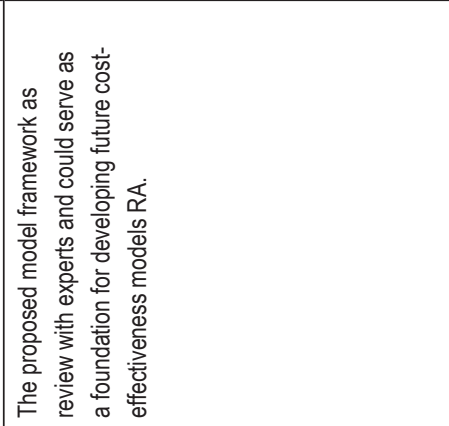 \\
\hline 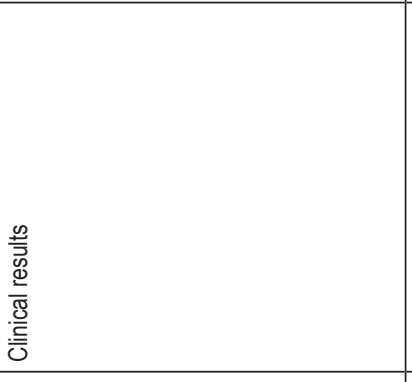 & 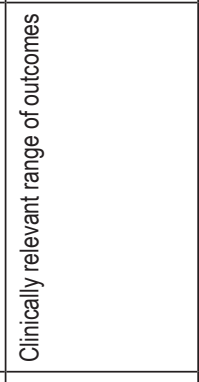 & 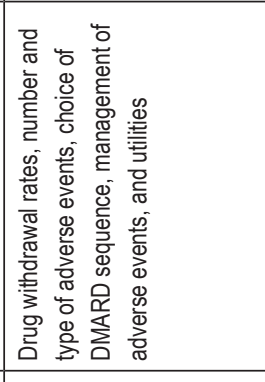 & 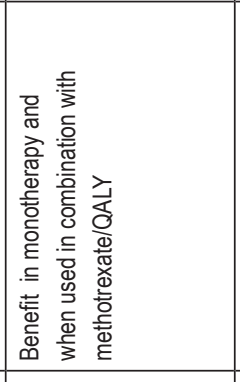 & 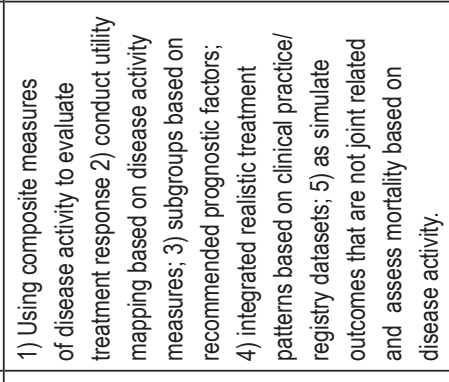 \\
\hline 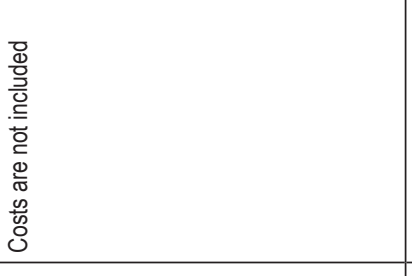 & 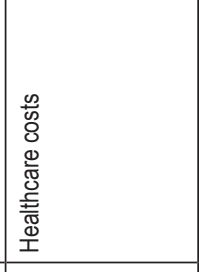 & 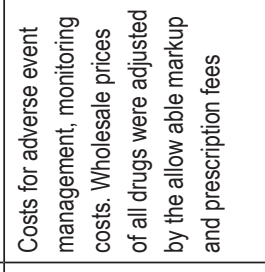 & 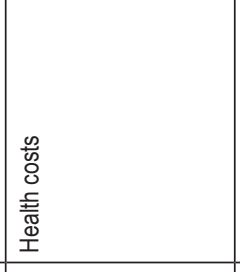 & 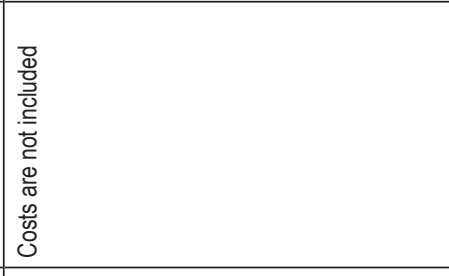 \\
\hline 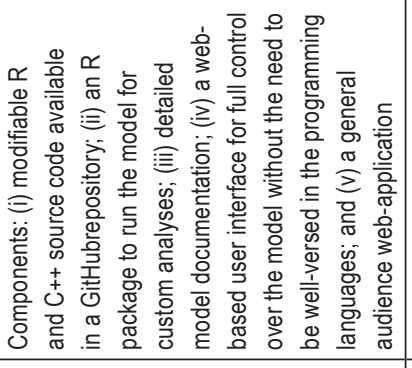 & 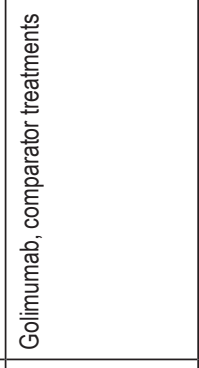 & 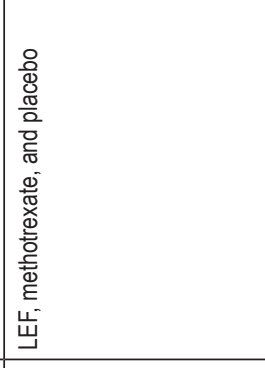 & 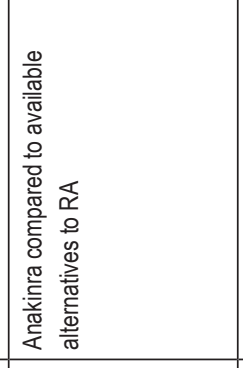 & 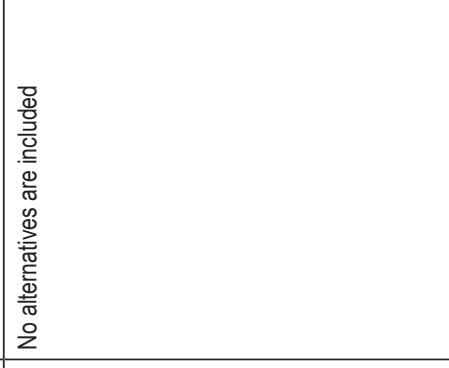 \\
\hline 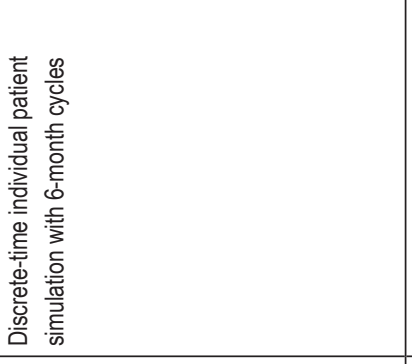 & 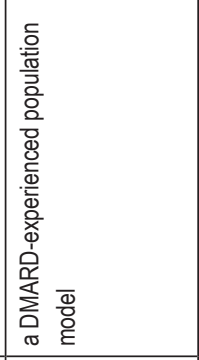 & 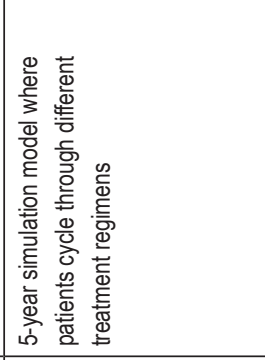 & 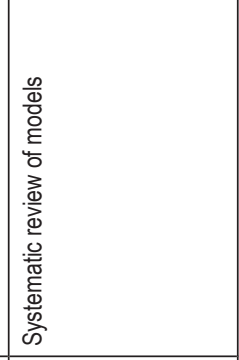 & 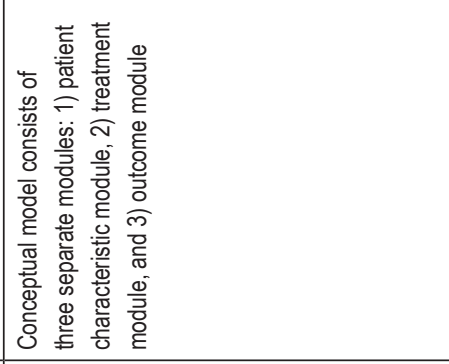 \\
\hline 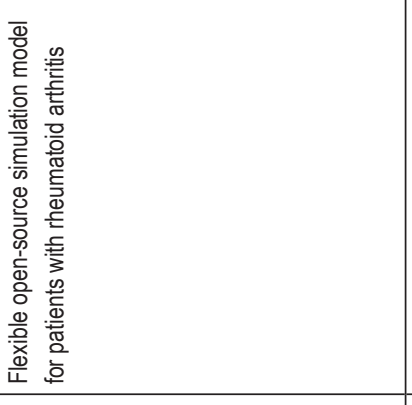 & 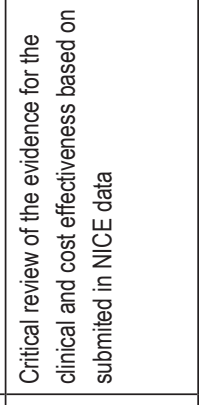 & 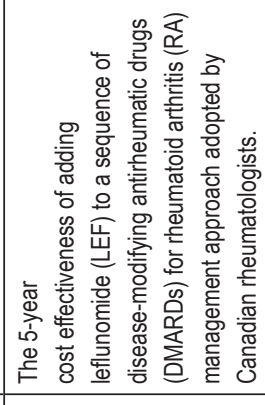 & 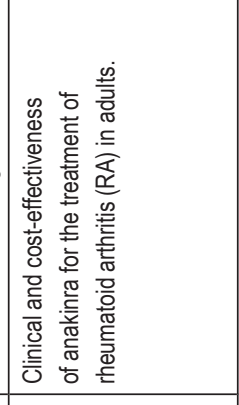 & 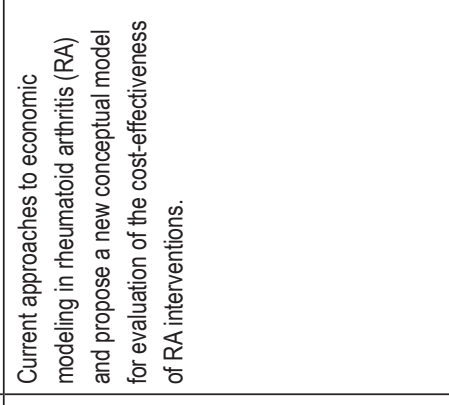 \\
\hline 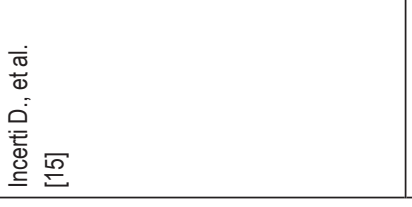 & 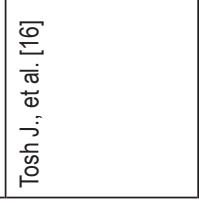 & 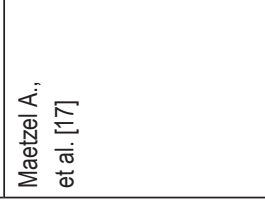 & 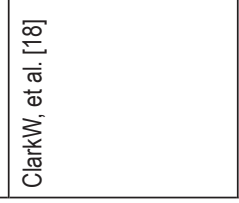 & 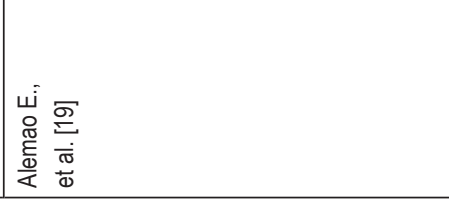 \\
\hline
\end{tabular}




\begin{tabular}{|c|c|c|c|c|c|}
\hline 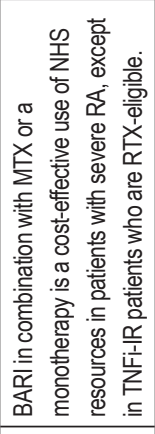 & 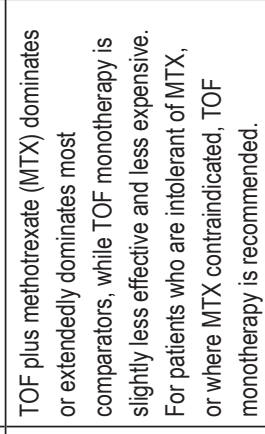 & 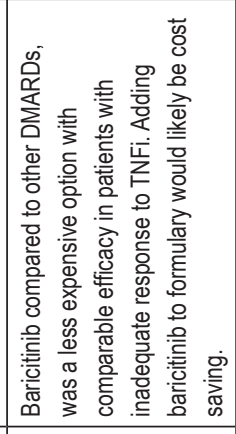 & 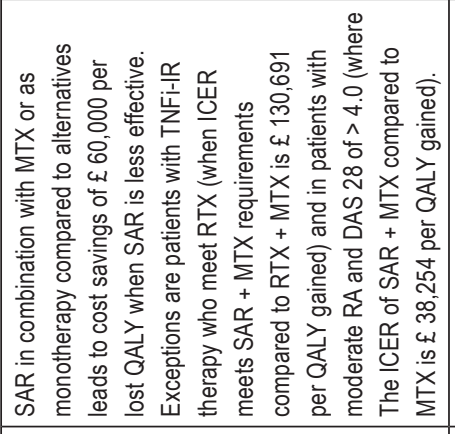 & 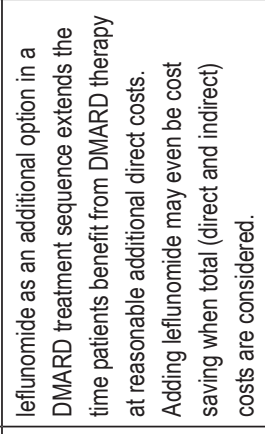 & 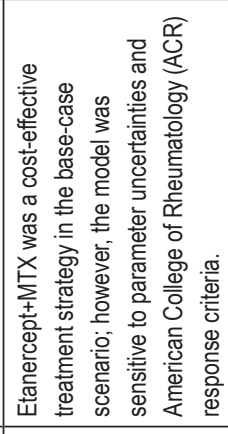 \\
\hline خे & خ̀ & 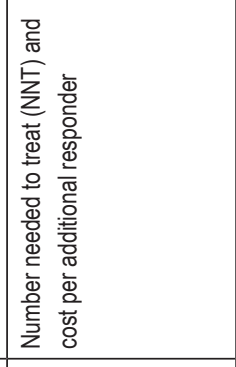 & 交 & 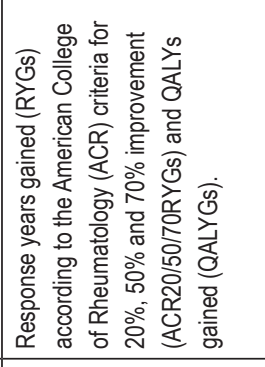 & 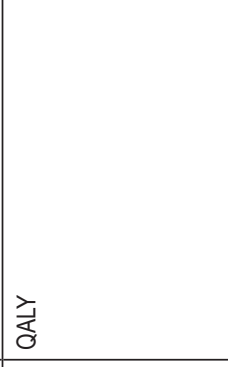 \\
\hline 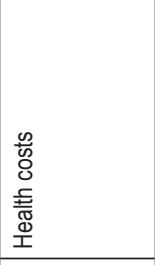 & 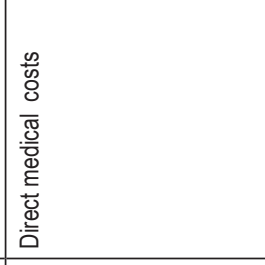 & 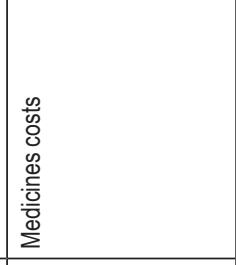 & 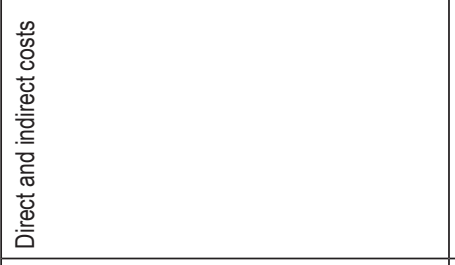 & 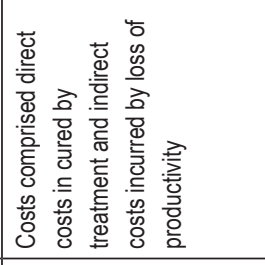 & 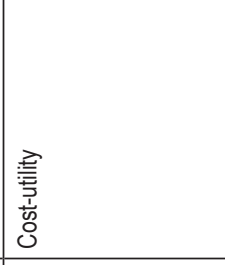 \\
\hline 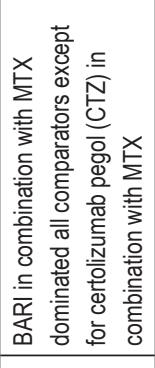 & 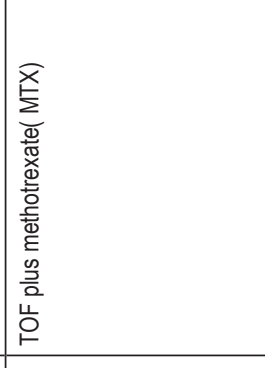 & 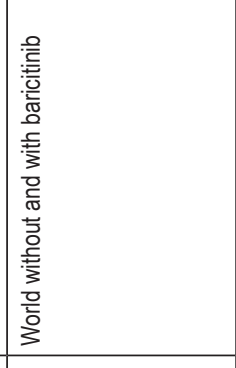 & 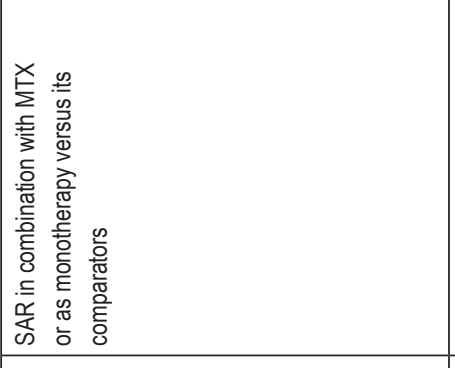 & 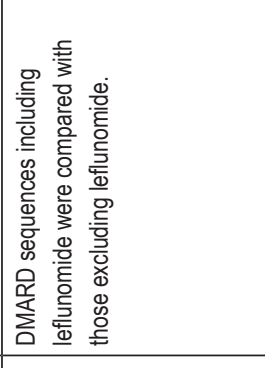 & 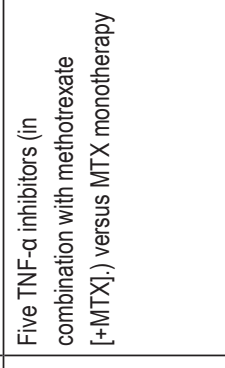 \\
\hline 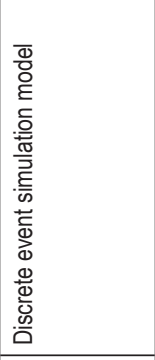 & 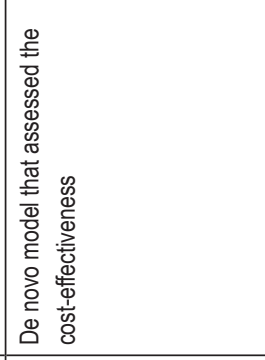 & 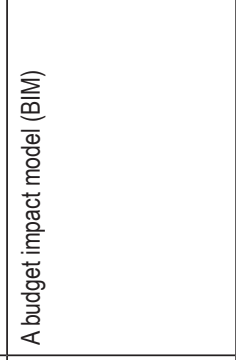 & 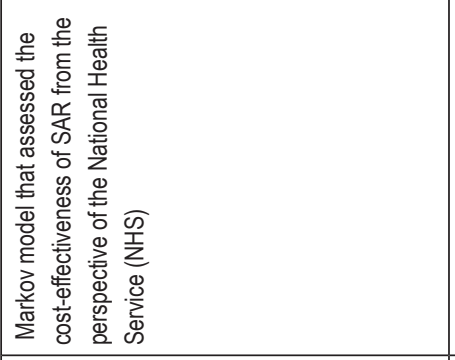 & 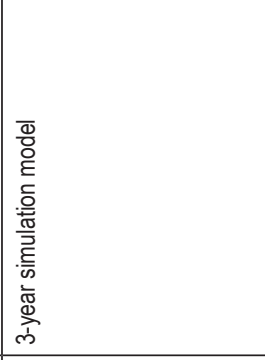 & 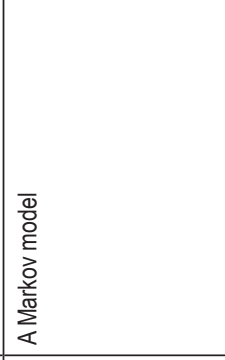 \\
\hline 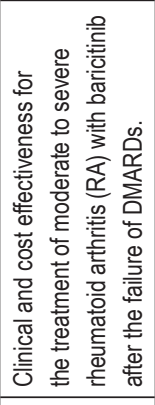 & 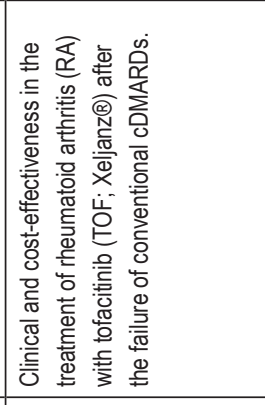 & 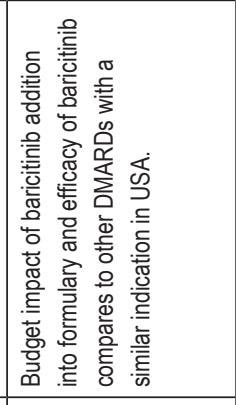 & 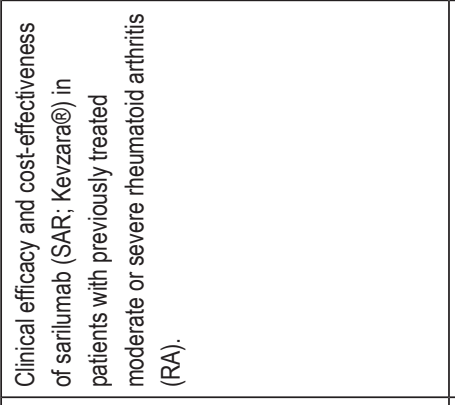 & 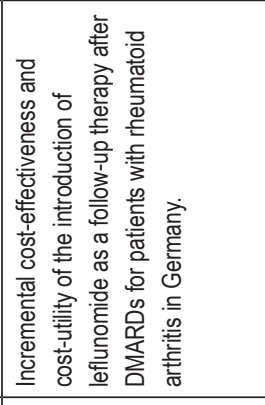 & 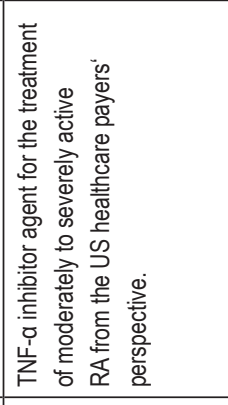 \\
\hline 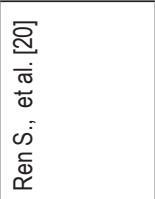 & 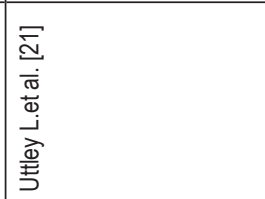 & 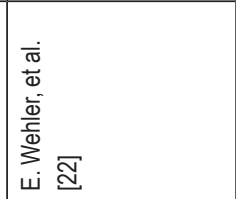 & 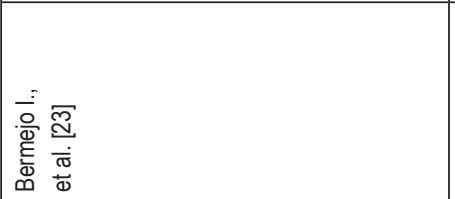 & 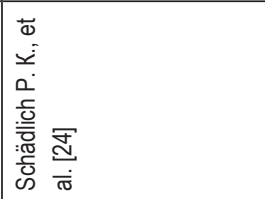 & 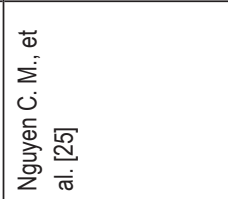 \\
\hline
\end{tabular}




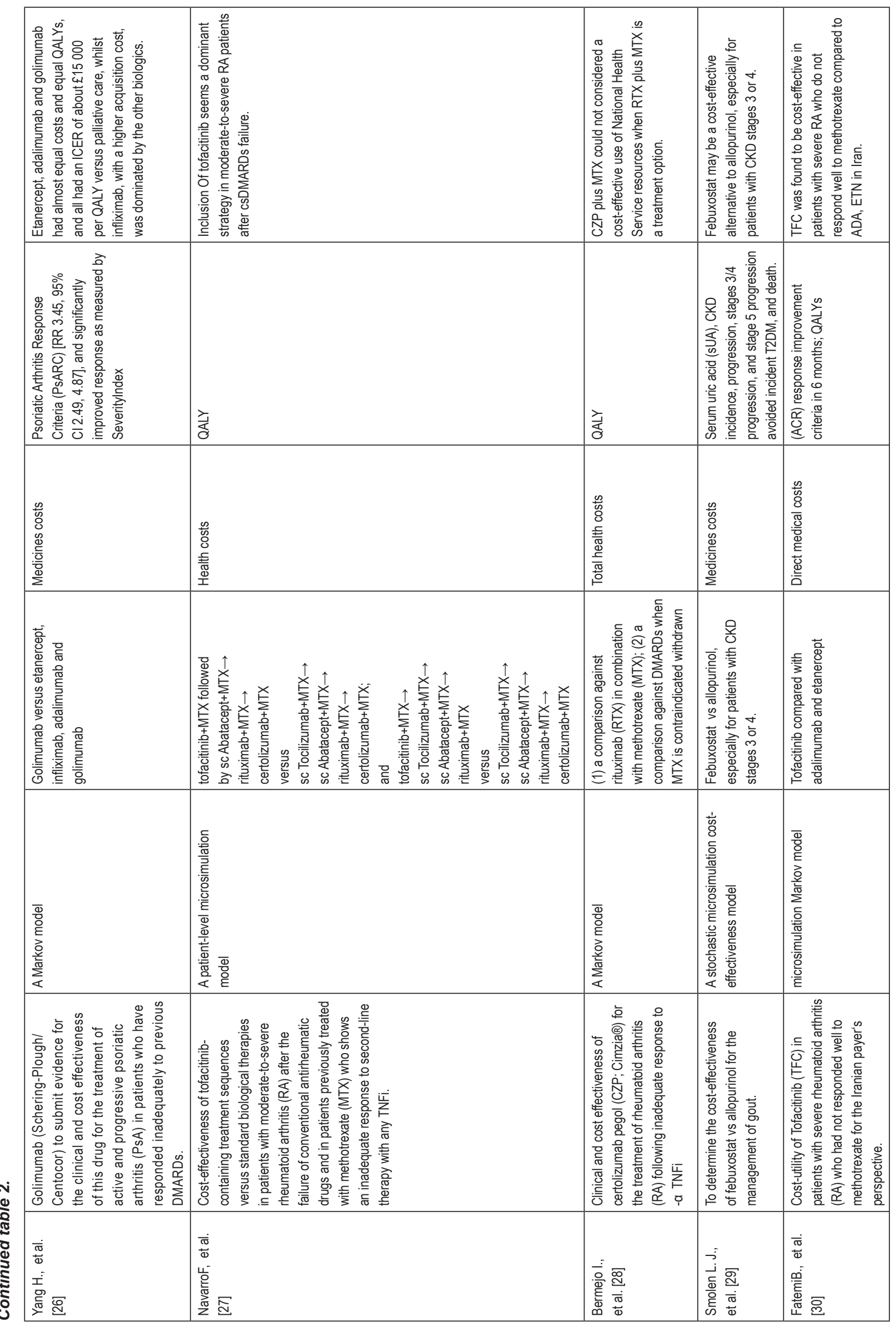




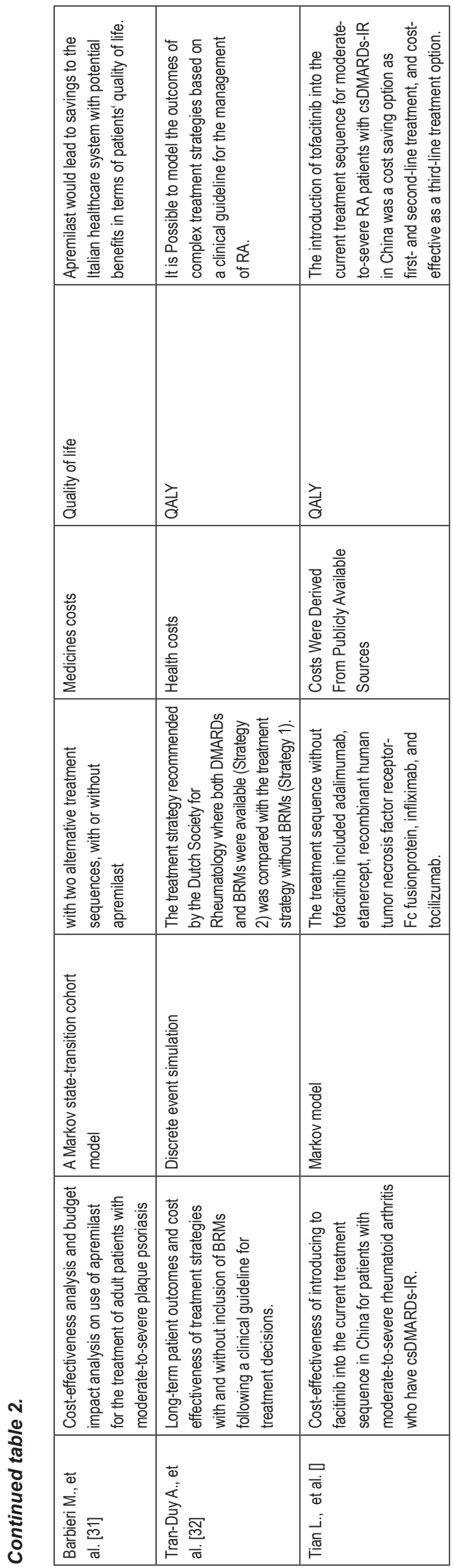

\section{Библиография / References}

1. Milne R. J. Pharmacoeconomic Models in Disease Management. A Guide for the Novice or the Perplexed. Dis Manag Health Out, 1998; 4: 119-134.

2. Caro JJ, Briggs AH, Siebert U, et al. Modeling good research practices - overview: a report of the ISPOR-SMDM Modeling Good Research Practices Task Force-1. Value Health. 2012;15(5):796-803.

3. Hay J., Evaluation and review of pharmacoeconomic models. Expert Opinion on Pharmacotherapy 2004; 5 (9): 186780, DOI: $10.1517 / 14656566.5 .9 .1867$

4. Hill-McManus D., Marshall S., Liu J., Willke R.J., Hughes D. A.. Linked Pharmacometric-Pharmacoeconomic Modeling and Simulation in Clinical Drug Development. Clinical Pharmacology \& Therapeutics 2021; 110 (1): 49-63 https://doi. org/10.1002/cpt.2051

5. Carta A., Conversano C. On the Use of Markov Models in Pharmacoeconomics: Pros and Cons and Implications for Policy Makers. Front. Public Health, 2020 | https://doi. org/10.3389/fpubh.2020.569500

6. Thomas D, Hiligsmann M, John D et al. Pharmacoeconomic analyses and modeling. In: Thomas D, editor. Clinical Pharmacy Education, Practice and Research. Amsterdam, NL: Elsevier (2019). p. 261-75. doi: 10.1016/B978-0-12-8142769.00018-0

7. Hoch JS, Briggs AH, Willan AR. Something old, something new, something borrowed, something blue: a framework for the marriage of health econometrics and cost-effectiveness analysis. Health Econ. (2002) 11:415-30. doi: 10.1002/hec.678

8. Tachkov K. Modelling in pharmacoeconomics - application and types of models. Star, Sofia, 2020.

9. Drummond M. F., Sculpher M. J., Torrance G. W et al. Methods for The Economic Evaluation of Health Care Programmes. Oxford Univ Press, London, 1998

10. Kobelt G., Jönsson L., Lindgren P., Young A., Eberhardt $\mathrm{K}$. Modeling the progression of rheumatoid arthritis: a two-country model to estimate costs and consequences of rheumatoid arthritis Arthritis Rheum. 2002; 46(9): 2310-9. doi: 10.1002/art.10471.

11. Scholz S., T. Mittendorf. Modeling rheumatoid arthritis using different techniques - a review of model construction and results. Health Economics Review, 2014, 4: 18

12. Bessette L., Risebrough N., Mittmann N. et al. Cost-utility of celecoxib use indifferent treatments trategies for osteoarthritis and rheumatoid arthritis from the Quebec healthcare system perspective. J Med Econ. 2009;12(3):246-58. doi: 10.3111/13696990903288970.

13. Russell A., Beresniak A., Bessette $L$ et al. Clin Rheumatol. 2009 Apr;28(4):403-12. doi: 10.1007/s10067-008-1060-4

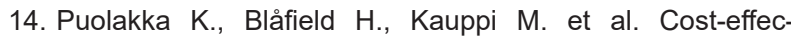
tiveness modelling of sequential biologic strategies for thetreatment of moderate to severe rheumatoid arthritis in Finland. Open Rheumatol J. 2012;6:38-43. doi: $10.2174 / 1874312901206010038$

15. Baser O., Burkan A., Baser E et al. Directmedicalcosts associated with rheumatoid arthritis in Turkey: analysis from National Claims Database Rheumatollnt. 2013;33(10):2577-84. doi: 10.1007/s00296-013-2782-4.

16. Iannazzo S., Benucci M., Favalli E.G. Tocilizumab after a first-linewithanti-TNF in rheumatoid arthritis: a cost-consequence analysis in the Italian setting Clin Exp Rheumatol. 2018;36(3):479-485. 
17. Purmonen T., Törmälehto S., Wahlman H., Puolakka K. Budgetimpactanalysis of secukinumab versus adalimumab in the treatment of ankylosing spondylitis. J Med Econ. 2019 Feb;22(2):151-157. doi: 10.1080/13696998.2018.1551227

18. Svarvar P, Aly A. Use ofthe ACCES model to predic the health economic impactofcelecoxibin patients with osteoarthritis or rheumatoid arthritis in Norway. Rheumatology (Oxford). 2000;39 (Suppl 2):43-50. doi: 10.1093/rheumatology/39.suppl_2.43.

19. Welsing P.M.J, Severens J.L., Hartman $M$ et al. The initial validation of a Markov model for the economic evaluation of (new) treatments for rheumatoid arthritis. Pharmacoeconomics. 2006; 24(10):1011-20. doi: 10.2165/00019053200624100-00008.

20. Oh K-T, Anis A H, Bae S-C. Pharmacoeconomic analysis of thiopurinemethyl transferase polymorphism screening by polymerasechainreaction for treatment with azathioprinein Korea. Rheumatology (Oxford) 2004 Feb;43(2):156-63. doi: 10.1093/rheumatology/keh001.

21. Harrison M., Marra C., Shojania K., Bansback N. Societal preferences for rheumatoid arthritis treatments: evidence from a discretechoiceexperiment. Rheumatology (Oxford). 2015 Oct;54(10):1816-25. doi: 10.1093/rheumatology/kev113.

22. Jutkowitz E., Alarid-Escudero F., Choi H. K et al. Prioritizing Future Researchon Allopurinol and Febuxostat for the Management of Gout: Valueof Information Analysis. Pharmacoeconomics. 2017;35(10):1073-1085. doi: 10.1007/ s40273-017-0526-0

23. Salinas-Escudero G., Vargas-Valencia J., García-García E.G et al. Cost-effectiveness analysisof etanercept compared with other biologic therapies in the treatment of rheumatoid arthritis. Rev Med Inst Mex Seguro Soc. Sep-Oct 2013;51(5):514-21.

24. Tanaka E., Inoue E., Yamaguchi R et al. Pharmacoeconomic analysis of biological disease modify in ganti rheumatic drugsin patients with rheumatoid arthritis basedonreal-world data from the IORRA observational cohort studyin Japan. Mod Rheumatol. 2017;27(2):227-236. doi: 10.1080/14397595.2016.1205799.

25. Hashemi-Meshkini A., Nikfar S., Glaser E et al. Cost-Effectiveness Analysisof Tocilizumab in Comparison with Infliximab in Iranian Rheumatoid Arthritis Patients with Inadequate Response to tDMARDs: A Multistage Markov Model. Value Health Reglssues. 2016; 9:42-48. doi: 10.1016/j. vhri.2015.10.003.

26. Incerti D., Curtis J. R., Shafrin J et al. A Flexible OpenSource Decision Model for Value Assessmentof Biologic Treatment for Rheumatoid Arthritis. Pharmacoeconomics. 2019;37(6):829-843. doi: 10.1007/s40273-018-00765-2.

27. Tosh J., Archer R., Davis $S$ et al. Golimumab for thetreatment of rheumatoid arthritis after the failure of previousdisease-modify in gantirheumatic drugs: a NICE single technology appraisal. Pharmacoeconomics. 2013;31(8):653-61. doi: 10.1007/s40273-013-0052-7

28. Maetzel A., Strand V., Tugwell $P$ et al. Cost-effectiveness of adding leflunomide to a 5-year strategy of conventional disease-modifying anti rheumatic drugsin patients with rheumatoid arthritis. Arthritis Rheum. 2002; 47(6):655-61. doi: 10.1002/art.10793

29. Clark W, Jobanputra P, Barton P, Burls A. The clinical and cost-effectiveness ofanakinra for the treatment of rheumatoid arthritis inadults: a systematic review and economican alysis. Health TechnolA ssess. 2004;8(18):iii-iv, ix-x, 1-105. doi: $10.3310 /$ hta8180.

30. Alemao E., Al M. J, Boonen A.A et al. Conceptual model for the health technology assessment of current and novel interventions in rheumatoid arthritis. PLoSOne. 2018 Oct 5;13(10):e0205013. doi: 10.1371/journal.pone.0205013

31. Ren S., Bermejo I., Simpson E., Wong R et al. Stevenson. Baricitinib for Previously Treated Moderateor Severe Rheumatoid Arthritis: An Evidence Review Group Perspective of a NICE Single Technology Appraisal. Pharmacoeconomics. 2018 Jul;36(7):769-778. doi: 10.1007/s40273-018-0616-7.

32. Uttley L., Bermejo I., Ren $S$ et al. Tofacitinib for Treating Rheumatoid Arthritis After the Failure of Disease-Modifying Anti-rheumatic Drugs: An Evidence Review Group Perspectiveof a NICE Single Technology Appraisal. Pharmacoeconomics. 2018;36(9):1063-1072. doi: 10.1007/ s40273-018-0639-0.

33. Wehler E., Boytsov N., Nicolay C et al. A Budgetlmpact and Cost Per Additional Responder Analysis for Baricitinib for theTreatmentof Moderate-to-Severe Rheumatoid Arthritisin Patients withan Inadequate Response to Tumor Necrosis Factorlnhibitorsinthe USA. Pharmacoeconomics. 2020 Jan;38(1):39-56. doi: 10.1007/s40273-019-00829-x.

34. Bermejo I., Ren S., Simpson E et al. Stevenson. Sarilumab for Previously-Treated Moderateor Severe Rheumatoid Arthritis: An Evidence Review Group Perspectiveof a NICE Single Technology Appraisal. Pharmacoeconomics. 2018; 36 (12): 1427-1437. doi: 10.1007/s40273-018-0677-7.

35. Schädlich P. K., Zeidler H., Zink Angela et al. Modelling cost-effectiveness and costutilityofsequential DMARD therapy in cluding leflunomide for rheumatoid arthritisin Germany: II. The contribution of leflunomide to efficiency. Pharmacoeconomics. 2005;23(4):395-420. doi: 10.2165/00019053200523040-00008.

36. Nguyen C. M., M. Bounthavong, M. Mendes, M. Christopher, J. Tran, R. Kazerooni, A. Morreale. Costutilityoftumournecrosisfactor- $\alpha$ inhibitors for rheumatoid arthritis: anapplicationof Bayesian methods for evidencesynthesisin a Markov model. Pharmacoeconomics. 2012; 30 (7): 575-93. doi: 10.2165/11594990-000000000-00000.

37. Yang H., Craig D., Epstein D et al. Golimumab for the treatment of psoriatic arthritis: a NICE single technology appraisal Pharmacoeconomics. 2012; 30 (4): 257-70. doi: 10.2165/11595920-000000000-00000.

38. Navarro F, Martinez-Sesmero J M, Balsa A et al. Cost-effectiveness analysis of treatment sequences containing to facitinib for the treatment of rheumatoid arthritisin Spain. Clin Rheumatol. 2020; 39 (10): 2919-2930. doi: 10.1007/s10067020-05087-3.

39. Bermejo I., Stevenson M., Archer R et al. Certolizumab Pegol for Treating Rheumatoid Arthritis Following Inadequate Response to a TNF- $\alpha$ Inhibitor: An Evidence Review Group Perspectiveof a NICE Single Technology Appraisal. Pharmacoeconomics. 2017; 35 (11): 1141-1151. doi: 10.1007/ s40273-017-0521-5.

40. Smolen L. J., Gahn J. C., Mitri G., Shiozawa A. Febuxostatin the management of gout: a cost-effectiveness analysis. J Med Econ. 2016;19(3):265-76. doi: 10.3111/13696998.2015.1116990.

41. Fatemi B., Rezaei S., Taheri S., Peiravian F. Cost-effectiveness analysis oftofacitinibcompared with adalimumab and etanercept inthetreatment of severe active rheumatoid arthritis; Iranian experience. Expert Rev Phar- 
macoecon Outcomes Res. 2021 Aug;21(4):775-784. doi: 10.1080/14737167.2021.1834384.

42. Barbieri M., Loconsole F., Migliore A., Capri S. A cost-effectiveness and budgetimpact analysis of apremilastin patients with psoriasisin the Italian setting. J Med Econ. 2020 Apr;23(4):362-370. doi: 10.1080/13696998.2019.1707209.

43. Tran-Duy A., Boonen A., Kievit W et al. Modelling out comes of complex treatment strategies following a clinical guideline for treatment decisions in patients with rheumatoi darthritis. Pharmacoeconomics. 2014 Oct;32(10):1015-28. doi: 10.1007/s40273-014-0184-4.

44. Tian L., Xiong X., Guo Q et al. Cost-Effectiveness of Tofacitinib for Patients with Moderate-to-Severe Rheumatoid Arthritisin China. Pharmacoeconomics. 2020;38(12):13451358. doi: 10.1007/s40273-020-00961-z.

45. Boyadzhieva, V., Stoilov, N., Ivanova, M., Stoilov, R.. Treatment of rheumatoid arthritis: csDMARDS versus bDMARDS. Prospective study to evaluate disease activity. Rheumatolo-

Постьпила за печат: 13.10.2020 г.

$\triangle$ Адрес за кореспонденция:

К. Ташков

Фармацевтичен фракултет

МУ - София

1000 София, България

e-mail: achkov@outlook.com gy (Bulgaria). 201;927, 1 (Apr. 2019), 3-15. DOI:https://doi. org/10.35465/27.1.2019.pp3-15.

46. Boyadzhieva, V., Stoilov, N. and Stoilov, R.. Assessment of health-related quality of life in patients with rheumatoid arthritis and analysis of its change during csDMARDS and bDMARDS therapy after one year of follow-up. Rheumatology (Bulgaria). 201;927, 3 (Sep. 2019), 29-43. DOI:https://doi. org/10.35465/27.3.2019.pp29-43.

47. Kobelt G: The cost-effectiveness of infliximab (Remicade(R)) in the treatment of rheumatoid arthritis in Sweden and the United Kingdom based on the ATTRACT study. Rheumatology 2003, 42(2):326-335.

48. Hashemi-Meshkini A., Nikfar S., Glaser E et al. Cost-Effectiveness Analysis of Tocilizumab in Comparison with Infliximab in Iranian Rheumatoid Arthritis Patients with Inadequate Response to tDMARDs: A Multistage Markov Model V A LUE IN HEALTH REGIONAL ISSUES 9C (2016) 42-48)

Submitted: 13.10 .2020

$\triangle$ Correspondence address:

K. Tachkov

Faculty fo Pharmacy

$\mathrm{MU}$ - Sofia

1000 Sofia, Bulgaria

e-mail: tachkov@outlook.com 